\title{
Guiding a Meaningful Experiential Learning Journey by Making It HIP Again
}

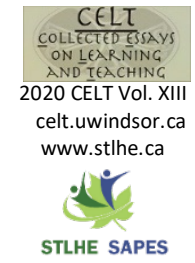

\author{
Lisa Endersby, Geneviève Maheux-Pelletier \\ York University
}

The definition of experiential education (EE) has both pedagogical and practical implications for higher education institutions. While there is increasing pressure to justify and quantify these experiences, we remain faced with the challenge of ensuring that a demonstration of breadth does not distract from the importance of meaningful depth both in and for student learning. This paper presents a potential reframing of conversations about experiential education and emphasizes the role of high impact practices (HIPs) in defining EE as more than an experience. The value, purpose, and challenges of integrating reflection into these experiences is highlighted through the lens of the defining characteristics of HIPs, supporting the development of meaningful, engaging opportunities for deeper learning.

La définition de l'enseignement fondé sur l'expérience (EE) est importante à la fois pour l'aspect pédagogique et pour l'aspect pratique de l'enseignement supérieur. Même si de plus en plus de voix réclament une clarification et une quantification de ce type d'expérience, la difficulté demeure la même: en démontrant l'étendue de l'expérience, il faut se garder de négliger la profondeur de l'apprentissage, qui est importante et chargée de sens. Dans notre article, nous proposons une avenue possible pour déplacer la conversation au sujet de l'enseignement fondé sur l'expérience en mettant l'accent sur le rôle des pratiques à incidence élevée dans l'EE conçu comme une notion dépassant celle d'expérience. Pour comprendre quelle valeur, quel but et quelles difficultés émergent de l'intégration de la réflexion à l'expérience, nous observons les choses à partir des traits caractéristiques des pratiques à incidence élevée de manière à rassembler les conditions pour un apprentissage en profondeur motivant et enrichissant.

E xperiential education (EE), also known as to work-integrated learning (WIL), is challenging to define for many academic programs as they strive to facilitate authentic opportunities for student learning, while also needing to demonstrate alignment with institutional priorities. In the current accountability climate, it is equally important for many institutions to report on the number of EE opportunities offered to students while taking concrete steps to provide high quality educational opportunities.

A common strategy to address this challenge has been to identify occurrences of EE by the experience itself (e.g., lab, internship, community service). While these experiences offer an opportunity for meaningful experiential learning to occur, a new challenge arises when we attempt to define EE based on the experience alone. At institutions across Ontario, lists of activities that 
qualify as EE are generated and categorized on a differing basis. These may include obvious categories of activities such as work-integrated learning (e.g., an internship or a practicum) and community-based activities (e.g., service learning). Less commonly included are co-curricular activities, such as studentled initiatives at Brock University (see Appendix A), and classroom centric activities at York University (see Appendix B), such as a project, a lab, or a guest speaker. A strict focus on the workplace, aligning explicitly with government directives, is used at the University of Guelph (see https://www.uoguelph.ca/experientiallearning/abo ut-el/experiential-learning-university-guelph ).

A narrow focus on work-integrated learning is restricting, yet the all-encompassing classroom category highlights the awkwardness that comes with defining EE by experience type. There is nothing intrinsically experiential about the use of visual media (e.g., at York) or a guest speaker visit (e.g., at Brock). We concede that most institutions offer a broader definition than the experience itself, explicitly mentioning the role of reflection as a critical component of the experiential learning cycle. However, the reference is usually brief and lacking enough substance to guide instructors in the implementation of a meaningful experiential learning process. Hence, in practice, the scope of experiential education is often narrowed to any or all real-world activities where students engage in some form of active or interactive learning. In this article, we argue that a focus on what the experience consists of and where it takes place is a necessary but insufficient criterion for designing impactful experiential learning opportunities.

Various stakeholders value and promote experiential education from a particular lens, leading to different definitions and ways of structuring experiential education to maximize learning. From a prospective student perspective, EE is valued as a means to acquire relevant work experience, applied knowledge, and practical skills for career readiness (Hanover Research, 2015) as employers are looking for well-rounded candidates with experience in relevant job sectors (Universities Canada, 2016). At the government and institutional levels, the value of EE is multi-faceted:

a) It is an educational strategy that helps students integrate knowledge and skills;

b) It provides relevant work experiences that give graduating students a competitive advantage (Ontario Ministry of Education, 2019);

c) It is positively associated with student retention (Kuh, 2008);

d) In the context of Ontario, and likely elsewhere, the proportion of students having engaged with EE is a metric used to measure the performance of publicly funded institutions (Ontario, 2018), which in turn can impact public funding.

From an educational lens, $\mathrm{EE}$ is an exciting pedagogical strategy that fosters deep engagement with course content by leveraging a concrete experience to bring real-world relevance to the classroom. These experiences are structured to directly and explicitly address intended learning outcomes and are most often augmented by reflection. Given these perspectives, it is clear that experiential education best serves the needs of all stakeholders when thoughtfully designed and integrated into curriculum from the experience itself and the scaffolding of learning opportunities across a given program to the structure and support provided to students as they learn to process experience through a critically reflective lens. Hence, an intentional focus on the entire learning process, as opposed to an emphasis on the experience alone, is essential.

In the next section, we discuss our definition of experiential education, one that has evolved from an attempt at integrating these multiple perspectives and experiences. The provincial government of Ontario has placed increasing importance on providing students with opportunities for experiential education during their university careers. We have drawn on external demands based on this context and internal needs to develop an expanded definition of 
experiential education that attempts to marry the pedagogical approach and practical implications that are both necessary to consider when doing this work.

We then explore the attributes of high impact practices as a way to ground experiential education in a framework that values and promotes a wholesome educational experience. In this lens, EE is viewed both as a pedagogical ideal and a practical anchor for graduates as they enter a competitive workforce. We then discuss how a wholesome educational experience is often made meaningful through the integration of reflection as a pedagogical strategy designed to deepen and solidify learning.

\section{What is Experiential Education?}

The term experiential education has seen a new surge in popularity in the province of Ontario in part due to a directive from the provincial government to ensure that all students "develop essential workplace skills" and can "make more informed decisions about their education and career path so they make a successful transition into the job market" (Ontario Ministry of Education, 2019, para. 2). This perspective highlights the concrete value of exposing students to a variety of experiences that allow them to explore career options related to their field, while also offering hands on opportunities to practice essential skills that will help them to be successful in whatever path they choose after graduation. These experiences may also help to bridge the perceived gap between what students are learning in the classroom and how it might relate to their future personal or professional goals. Experiential education is thus an important tool for supporting meaning making for students.

Our definition of experiential education is "a pedagogical approach that includes an experience, rather than defining the experience, and only the experience, as experiential". Here, we make a subtle, but crucial distinction between experience and experiential. While students will have many experiences throughout their time at their institution of higher learning, both inside and outside of the classroom, not all of these experiences are experiential. As we define it in our workshops and resources, an experiential education approach involves "creating an opportunity for student learning that encourages critical observation, reflection, analysis, and synthesis to promote deeper learning for personal and professional growth". What this means, fundamentally, is that our conversations about experiential education focus on distinguishing experiences that intentionally and explicitly offer students the opportunity to develop essential intellectual skills while also engaging them in critical reflection to help make this learning, and the learning process, more valuable, meaningful, and explicit.

This pedagogical approach blends theory and coursework with practical, concrete experience. As students are acquiring real life experience, reflection helps them to make connections among theory, coursework, and diverse real-world scenarios. Reflection as a tool for making connections between theory and practice also supports students in deepening their understanding of the theories and ideas they engage with in the classroom. It may be that students can identify key concepts, but the more cognitively complex skills like analysis and synthesis (Bloom, Engelhart, Furst, Hill, \& Krathwohl, 1956) are often better supported when students are actively engaged in working with and applying these ideas in real time, rather than simply reading about how they may be used hypothetically or conceptually (Laird, Shoup, Kuh, \& Schwarz, 2008).

At our institution, for example, experiential activities are clustered under three categories: classroom-focused, community-focused, and workfocused. Taken together, these activities look quite different, but all fall under the EE umbrella. Given this large spectrum, criteria other than an activity label are needed not only to help determine the degree of 'EE-ness' of an activity claimed to be experiential, but also to enhance its quality. Thus, we turn to the characteristics of High Impact Practice as a way to capture and enhance the richness of experiential education.

\section{What is Experiential Education?}


Active learning fosters deep engagement with course content, creating educational contexts and practices that encourage students to meet the intended learning outcomes with both enthusiasm and perseverance. In the realm of experiential education, learning activities are designed to leverage a concrete experience by bringing a real-world lens to a course or program, thus heightening relevance, sustaining interest, bridging the gap between theory and practice, and encouraging group bonding through shared experiences. While experiential activities generate the context through which these attributes can emerge, a definition of experiential education focused on the experience itself does not capture them. In fact, such a definition frames experiential education as tokenism rather than an intentionally designed learning activity. High Impact Practices (HIPs) are rich learning opportunities positively associated with student retention and success (Kuh, 2008). They are characterised by engagement indicators that further define and specify what to look for when creating HIPs. Looking for and enabling these characteristics serves to deepen learning and elevate student engagement. Below, we review each of these attributes and make explicit connections to experiential activities. This brings to the fore what we consider to be the markers of a well-designed experiential education activity. Taken together, these characteristics contribute to making a particular teaching and learning strategy a robust EE activity. We then present a set of guiding questions to orient educators as they design experiential activities with impactful learning as an explicit goal.

\section{Time and Effort in Completing Purposeful Tasks}

Purposeful, authentic tasks lead to greater student engagement and higher order learning. In the context of experiential education, the amount of time and cognitive effort required to complete a task may be an important distinguishing factor between an activity that involves some form of active learning (e.g., think, pair share) from classroom-focused EE activity, such as an authentic interactive case study revisited regularly throughout a course. Such activities require frequent decision-making and as such "deepen students' investment in the activity as well as their commitment to their academic program" (Kuh, 2008, n.p.).

\section{Meaningful and Ongoing Interactions with Peers and Instructors}

High Impact Practices demand regular face-to-face interactions with peers and instructor "about substantive matters" (Kuh, 2008, n.p.) because they require considerable time and effort. These interactions provide opportunities to check in, learn with and from one another, and receive feedback to support deeper or more meaningful learning. For example, undergraduate students engaged in a research project with a professor, or students actively involved in co-curricular activities coordinated by a College Head are possible contexts where meaningful interaction with peers and professor can extend learning beyond the classroom.

\section{Frequent and Rich Opportunities for Feedback}

Through interactions with their professors and others, HIPs afford students with opportunities to receive timely feedback throughout the learning process. Students may receive informal and formal assessment of their performance through their submitted coursework by engaging in peer assessment activities facilitated by the instructor, or though being evaluated by their practicum coordinator or site supervisor. As a result, they are more likely to feel supported as they learn new skills and content knowledge applicable outside the conventional classroom.

\section{Opportunities to Discover the Relevance of Content Through Authentic Experiences}

High Impact Practices encompass a defining experience, one that "deepens learning and brings one's values and beliefs into awareness; it helps 
students develop the ability to take the measure of events and actions and put them in perspective" (Kuh, 2008, n.p.). When the experience is authentic, students acquire knowledge and intellectual skills that equip them to understand how they and their field of study relate to their broader context. Any real-world or real-world-like experiences, including simulations, case studies, and role play, may serve as opportunities to understand if and how their newly acquired knowledge applies beyond an academic setting and to generate an academically rigorous response to the issue they observe and experience through critical reflection.

\section{Communicate Performance Expectations at Appropriate Levels}

The rich experiences afforded by HIPs occur "in the context of a coherent, academically challenging curriculum that appropriately infuses opportunities for active, collaborative learning" (Kuh, 2008, n.p.). From a course or program design perspective, this means both the mapping of HIPs to a broader programatic learning trajectory, as well as the explicit articulation between experiential activities and intended learning outcomes at an appropriately challenging level of cognitive complexity. Learning outcomes serve as the mechanism through which performance expectations are set and communicated directly to students.

\section{Structured Opportunities to Reflect and Integrate Learning}

Students have meaningful opportunities to integrate, synthesize, and apply academic and practical knowledge as they experience an intentionally designed high impact practice. We explore the intricacies of providing meaningful opportunities for reflection and consider how reflection as pedagogy can intentionally and methodically integrate the other characteristics of HIPs. A summary of High Impact Practices is provided in Table 1 (see following page), with a set of guiding questions for faculty looking to explore how the characteristics of High Impact
Practices may be more intentionally integrated into an in class or out of class experience.

Taken together, the characteristics of a High Impact Practice offer a means to structure and organize the experience students engage in as part of an experiential education opportunity. They serve as reminders as we aim to create and facilitate meaningful, accessible, and authentic experiences through which deep learning can occur. While embedding all of them in one experience may not be possible or even desirable, focusing on a few characteristics will help enhance the quality and impact of an experiential activity.

\section{High Impact Practice and the Role of Reflection}

An early and well-cited theory on experiential education developed by David Kolb (1984) is a helpful, foundational approach to understanding experiential education as a process rather than a single product or experience. Beginning with the Concrete Experience itself, Kolb's cycle identifies Reflective or Reflexive Observation as essential to this learning process. At this stage, students are no longer passive participants. Instead, they take on the role of critical, engaged observers, collecting information to support later analysis and deeper learning. Some of this deeper learning happens during what Kolb labels as Abstract Conceptualization, where students begin to make connections and find meaning between theory from textbooks and lectures and how, where, and if these ideas appeared during their experience. Deeper learning is encouraged through practical application or Active Experimentation, where students can apply this knowledge to practice using or applying these 


\section{Table 1}

\section{Guiding Questions for High Impact Practice in Experiential Learning}

\section{High Impact Practice}

Requiring considering time and effort in completing purposeful tasks

Facilitating meaningful and ongoing interactions with peers and the instructor

Exposing students to diversity of thought and experiences

Providing frequent and rich opportunities for feedback

Offering opportunities to discover the relevance of content through authentic experiences

Setting performance expectations at appropriate levels and communicating these expectations

Providing context for regular, structured opportunities to reflect and integrate learning

\section{Guiding Questions for High Impact Experiential} Activities

- How will you negotiate 'time on task' with appropriate cognitive complexity of activities?

- Will your students have the necessary time required to complete the tasks involved? What makes the activities authentic and meaningful?

Does the process encourage frequent decision making and critical thinking?

- How will you be present as part of your students' experience(s)?

- How will you encourage meaningful interaction amongst the students' peers?

- How will you provide just-in-time support?

- How will you engage in dialogue with your students?

- How will you support and encourage a diversity of thoughts, perspectives, and ideas throughout the students' experience(s)?

- How will you create a safe, brave space for this dialogue while challenging \& supporting students in reconsidering their ways of thinking?

How can different perspectives be made salient, relevant, and important?

- How will your students know if they are on the right track?

- At what point(s) throughout the experience do you offer students a timely opportunity to self assess their progress, or to be assess by you and/or their peers?

How might you ensure that students have opportunities for both 'checking in' as well as deep(er) discussion and helpful feedback?

- What can you incorporate in the design of that experience (e.g. context cues, descriptors) to enhance its authenticity?

- How close to 'real life' is the experience your students are engaging in?

- Are students encouraged to provide an emotional response to the experience in addition to engaging with it intellectually?

How can you encourage students to draw parallels, compare, and contrast the experience and real-life encounters?

- How will you encourage an academically rigorous yet appropriately challenging experience?

How will your students know what is expected of them and how (and if) they have met these expectations?

- How and when will you provide students with the opportunity to reflect on what they have experienced and what they are learning?

- How might students work to integrate, analyze, and synthetize the ideas and information they are collecting throughout these experiences?

Will students have opportunities to reflect before, during and after these experiences? 
new ideas, much as a scientist would test a new hypothesis in an experiment or research study.

While Kolb's cycle is an important foundation for understanding this pedagogical approach to deeper learning, many faculty find it challenging to facilitate, integrate, or assess the essential elements of critical reflection. Instructors may also miss out on important opportunities to structure and support these experiences in a way that provides students with the best chance at learning to reflect and finding time and space to reflect at all. Hence, we turn to Ryan (2013), whose model of critical reflection draws on theory yet is grounded in practical, measurable terms. Importantly, she asserts that reflection is not an intuitive skill and, in fact, that "students can and should be taught how to reflect in deep, critical and transformative ways to engender sustainable learning practices" (p. 145). Understanding reflection as a skill helps to further augment the value of experiential education by offering a path through which students may acquire essential competencies in critical thinking.

Ryan's model speaks to different levels or layers of reflection (summarized in Table 2), though it is also valuable to consider these levels as stages in a cyclical process. Much like Kolb's cycle, this framework allows for a necessary flexibility when implementing this model with students. Students will be at many different stages and be subject to a variety of contextual variables. This means that they may enter into this cycle at a variety of points and may be expected to demonstrate different levels or depths of reflection depending on, for example, the instructor's desired learning outcomes for their course, or the students' previous experience with or exposure to reflection as well as their level of familiarity with the content. Taken as a whole, Ryan's model demonstrates the utility of defining reflection as the act of noticing what happens, relating to the various happenings at a personal level, making connections with theory, and applying or practicing this new knowledge, in observable, measurable terms that can be taught and assessed.

Early exposure to reflection may be valuable in supporting students in noticing aspects of their
Table 2

Ryan's (2013) Levels of Reflection (adapted)

\begin{tabular}{ll} 
Reporting \& & $\begin{array}{l}\text { Students are taught to } \\
\text { notice aspects of their } \\
\text { experience, form } \\
\text { opinions, and identify an } \\
\text { initial emotional } \\
\text { response to an issue or } \\
\text { incident. }\end{array}$ \\
\hline Relating & $\begin{array}{l}\text { Students make } \\
\text { connections between } \\
\text { the experience or issue } \\
\text { with their skills, } \\
\text { knowledge, and/or prior } \\
\text { experiences. }\end{array}$ \\
& $\begin{array}{l}\text { Students' responses } \\
\text { move from a personal to } \\
\text { more intellectually } \\
\text { rigorous response; Refer } \\
\text { to and connect with } \\
\text { relevant theories and/or } \\
\text { literature. }\end{array}$ \\
& $\begin{array}{l}\text { Students integrate new } \\
\text { knowledge and make a } \\
\text { plan for action; How will } \\
\text { they use these new } \\
\text { insights and/or ideas in } \\
\text { future experiences? }\end{array}$ \\
\hline Reconstructing
\end{tabular}

experience, including what some practitioners have called critical incidents (Brookfield, 1995; Gilstrap \& Dupree, 2008). In our work, we have combined two of Ryan's early levels, Reporting \& Responding, to highlight the importance of constructing and facilitating an experience where students are prompted to pay attention to key elements of their experience and generating an initial response to it. These key elements may be defined in a variety of ways and for a variety of different purposes, but the central goal remains to encourage students to embrace a critical stance as they enter into and navigate a new learning experience. As a student 
moves through an experience, they may begin to make connections between what they are experiencing and their own skills, knowledge, and/or their own prior experiences that may feel similar to (or different from) this new opportunity. Ryan (2013) calls this stage Relating to emphasize the making of connections as a critical component of reflection. These connections are further emphasized and practiced in the next stage, Reasoning, where students begin the more academically rigorous work of reflection by connecting these experiences to relevant theories and/or literature taught in the classroom. This myriad of connections, from the personal to the academically informed, will eventually lead to what Ryan calls Reconstructing, where previously made connections enable some cognitive restructuring and lead to a tangible hypothesis or potential plan of action that supports students in further integrating this new knowledge.

\section{Reflection as Pedagogy}

Opportunities for regular, scaffolded reflection are critical to experiential learning. Ryan's framework provides students with a method for leveraging experience into an intellectually rigorous endeavour. At the same time, reflective activities can be designed to focus attention on, and at times enhance, other HIP attributes. As an interactive process, reflection takes considerable time and effort; it can help reveal the importance of interactions and ongoing collaboration in constructing knowledge and facilitate a feedback loop for self, as well as between peers and with their instructor. Leaming through reflection, and learning how to reflect, may itself be its own practice that requires a unique, structured, and intentional approach.

As Ryan (2013) suggests, reflection may be a common human activity or habit, but it is not an intuitive skill. This way of critical thinking often requires students to develop an awareness of their own metacognitive patterns or habits while also practicing taking on multiple, diverse, and at times conflicting perspectives when being introduced to new theories or concepts. These goals for our students demand a less intuitive approach to teaching, including designing appropriate activities and prompts that help students to practice these skills. It also means that our activities must include some opportunity for debrief and discussion where the knowledge gained and learning experienced through these activities can be made more explicit. Reflection can be an invaluable tool for surfacing assumptions, habits, and challenges related to how students learn (or think they learn). Modelling and experiencing this process while also making space for these ideas to be pondered and shared can lead to deeper learning and incredibly meaningful interactions in the classroom. As students learn to reflect, it is important to first develop a shared understanding of the role and expectations around reflection and establish scaffolded goals in support of the development of reflective skills (Coulson \& Harvey, 2013). For example, an entry-level course will aim to establish reflection as a response to the learning process, initially targeting levels 1 and 2 of Ryan's model. Levels 3 and 4 can be introduced and practiced gradually.

Teaching and learning reflection as a skill also implies that reflection can be used, practiced, and experienced in a multitude of ways. For example, while most students may think of reflection as a way to look back on an experience (reflection on action) (Schön, 1983), it is helpful to also consider how students may engage in reflection before action (Coulson \& Harvey, 2013). How might one prepare students to notice, evaluate, analyze, and plan for an experience? The opportunity to facilitate reflection in action (Coulson \& Harvey, 2013), where students can begin to think about and explore their practice, behaviours, and insights as they occur, can also be essential in helping students navigate an experience, explore its relevance, and regulate thought and emotions. Reflection as a skill, much like many other competencies, cannot simply be defined by a particular instance, context, or situation. It is a fluid, flexible, and at times cyclical process that encourages students to learn deeply, examine ideas critically, and engage meaningfully in exploring both a learning 
experience and how they as students can and will continue to learn best.

The act and art of critical reflection must also include a pragmatic approach to assessing student learning and evaluating their progress toward our intended learning outcomes. While the goal of engaging students in experiential education may be to help them learn new knowledge or develop important skills, we may also wish to assess their ability to reason, think critically, and make connections, particularly as they relate to explicitly stated learning outcomes. A necessary consideration when assessing experiential education, then, is to distinguish between monitoring whether or how students reflect and how they demonstrate successful achievement of or progress toward achieving intended learning outcomes. Assessment is also a complex undertaking in reflection; as instructors, we may be hesitant to assess the content of a reflection for fear of judging very personal feelings or thoughts. However, the academic lens we place on reflective expression (in writing or through other means) emphasizes that students can and must feel free to share their own ideas or opinions, but that this sharing must still be rooted in rigour and respect. Ryan's framework is once again helpful here to distinguish between process and content. While in our view, the process of reflection can be assessed, we are not certain that the content of reflection ought to be scrutinized or given a mark.

\section{Conclusion}

This article articulates our dissatisfaction with an activity-centric definition of experiential education. At institutions where classroom activities such as a guest speakers are framed as EE, an activity-centric definition of experiential education is deceiving. While it makes reporting easier, it does not capture the many facets of the experiential learning process.

Given that high-impact practices encompass many activities often labelled as experiential, we propose that focusing on what makes High Impact Practices 'high-impact'can go a long way in intentionally creating a rich learning environment around the focal experience. HIPs offer an appropriately complex academic challenge that requires time and effort. They transform the learning process into a collaborative endeavour through which students have opportunities to interact with peers and faculty, consider perspectives other than their own, receive ongoing feedback, and discover the relevance of what they are learning through authentic experiences. HIPs are meaningful because they are explicitly aligned with the curriculum. These attributes can give breadth and depth to the reflective activities facilitated by the instructor, particularly when students are encouraged to notice and respond to aspects of their experience, relate it to what they know, develop an intellectual understanding based on theory, and restructure their knowledge.

We agree that a guest speaker visit does not compare to a semester-long internship. Yet, if a community member comes to class with an academic challenge that has a clear connection to course content, fosters active engagement, offers a window into a real-life challenge that pushes students to consider realities other than their own, all the while nurturing reciprocal learning leveraged by reflection, then we are prepared to make it count as EE. We would hope, however, that this activity is embedded in a curricular trajectory that includes a variety of EE activities requiring more intense HIP attributes as students learn to make sense of increasing complex experiences through critical reflection.

\section{References}

Bloom, B. S. (Ed.), Engelhart, D. R., Furst, E. J., Hill, W. H., \& Krathwohl, D. R. (1956). Taxonomy of educational objectives: The classification of educational goals. Handbook I: Cognitive domain. New York, NY: David McKay.

Brookfield, S. (1995). Becoming a critically reflective teacher. San Francisco: Jossey-Bass.

Coulson, D., \& Harvey, M. (2013). Scaffolding student reflection for experience-based learning: A framework. Teaching in Higher Education, 18(4), 401-413. 
Gilstrap, D. L., \& Dupree, J. (2008). Assessing learning, critical reflection, and quality educational outcomes: The critical incident questionnaire. College \& Research Libraries, 69(5), 407-426.

Hanover Research. (2015). Best Practices in Experiential Learning at Liberal Arts Institutions. Retrieved September 25, 2019 from https://www.whitman.edu/Documents/Ne wsroom/Hanover $\% 20$ Research $\% 20$ $\% 20 \mathrm{Best} \% 20 \mathrm{Practices} \% 20 \mathrm{in} \% 20$ Experienti al $\% 20$ Learning $\% 20$ at $\% 20$ Liberal $\% 20 \mathrm{Arts}^{2} \%$ 20Institutions.pdf

Kolb, D. A. (1984). Experiential learning: Experience as the source of learning and development. Englewood Cliffs, NJ: Prentice Hall.

Kuh, G. D. (2008). High-impact educational practices: What they are, who has access to them, and why they matter. Washington, DC:Association of American Colleges and Universities.

Laird, T. F. N., Shoup, R., Kuh, G. D., \& Schwarz, M. J. (2008). The effects of discipline on deep approaches to student learning and college outcomes. Research in Higher Education, 49(6), 469-494.

Ontario (2018). College and University Strategic Mandate Agreements, 2017-2020. Retrieved September 28, 2019 from https://www.ontario.ca/page/college-anduniversity-strategic-mandate-agreements2017-2020.

Ontario Ministry of Education (2019, June). Experiential Learning. Retrieved from http://www.edu.gov.on.ca/eng/general/ele $\mathrm{msec} /$ job/passport/index.html

Ryan, M. (2013). The pedagogical balancing act: Teaching reflection in higher education. Teaching in Higher Education, 18(2), 144-155.

Schön, D. (1983). The reflective practitioner: How professionals think in action. New York, NY: Basic Books.

Universities Canada (2016). The Future of the Liberal Arts: A Global Conversation. Retrieved September 25, 2019 from https://www.univcan.ca/wpcontent/uploads/2016/09/the-future-of- the-liberal-arts-workshop-report-march2016accessible.pdf

\section{Biographies}

Geneviève Maheux-Pelletier, $\mathrm{PhD}$, is an educational developer, educator, and leader with two decades of experience in higher education. As the director of the Teaching Commons (York University), her work and scholarship focus on fostering a culture that values active learning.

Lisa Endersby, MEd, is an educational developer with the Teaching Commons (York University), supporting faculty in experiential education and cultivating a reflective practice. She has over 10 years of experience in higher education spanning positions in leadership development, career services, and service learning. 


\title{
Appendix A
}

\section{Experiential Education Categories Brock University}

\begin{abstract}
Experiential Education:
"Experiential education is a philosophy that informs many methodologies in which educators purposefully eng age with learners in direct experience and focused reflection in order to increase knowledge, develop skills, clarify values, and develop people's capacity to contribute to their communities." Association for Experiential
\end{abstract} Educotion.

\begin{tabular}{|c|c|}
\hline TYPE & CATEGORIES \\
\hline \multicolumn{2}{|c|}{$\begin{array}{l}\text { CURRICULAR - All of the following activities are part of a course requirements where students will receive a } \\
\text { grade for the activity. }\end{array}$} \\
\hline Conference Participation & $\begin{array}{l}\text { Develop, plan, coordinate, attend or present an original work at a } \\
\text { conference or exhibition. }\end{array}$ \\
\hline Consulting Project & $\begin{array}{l}\text { Work with a client to identify issues or opportunities and develop and/or } \\
\text { implement solutions and/or strategies. }\end{array}$ \\
\hline Co-op & $\begin{array}{l}\text { Alternate academic study with paid work terms to ga in relevant knowledge } \\
\text { of the industry or workplace. }\end{array}$ \\
\hline Creative or Physical Practice & $\begin{array}{l}\text { Develop artistic, physical, technical, management or production skills } \\
\text { through intensive embodied and/or practice-based experiences. }\end{array}$ \\
\hline Creative Performance or Exhibit & $\begin{array}{l}\text { Produce, manage, curate or participate in a dramatic, artistic, dance or } \\
\text { musical performance or exhibit for an audience (virtual, live). }\end{array}$ \\
\hline $\begin{array}{l}\text { Creative, Entrepreneurship or } \\
\text { Design Project }\end{array}$ & $\begin{array}{l}\text { Identify problems and prototype/test solutions to create a final artistic, } \\
\text { scientific, business or other project. }\end{array}$ \\
\hline Events & $\begin{array}{l}\text { Develop, deliver or attend an event in order to network with community } \\
\text { partners and present and gather feedback on projects and ideas. }\end{array}$ \\
\hline $\begin{array}{l}\text { Experiential Research Project } \\
\text { (Graduate level) }\end{array}$ & $\begin{array}{l}\text { Develop and complete a research thesis/dissertation through systematic } \\
\text { imvestigation, discovery, synthes is and/or application of information } \\
\text { designed to solve a specific problem or answer an original research } \\
\text { question. }\end{array}$ \\
\hline $\begin{array}{l}\text { Experiential Research Project } \\
\text { (Undergraduate level) }\end{array}$ & $\begin{array}{l}\text { Develop and complete a major research paper or thesis project through } \\
\text { discovery, synthesis, and/or application of information to solve a specific } \\
\text { problem or question. }\end{array}$ \\
\hline Field Experience (Short Term) & $\begin{array}{l}\text { Explore academic content in a purposeful way outside the class room } \\
\text { through short-term field trips and/or field-work (less than } 20 \text { hours) in } \\
\text { Canada }\end{array}$ \\
\hline Field Experience (Long Term) & $\begin{array}{l}\text { Intensive and immersive time in the field ( } 21+\text { hours) to study and apply } \\
\text { academic concepts within Canada. }\end{array}$ \\
\hline $\begin{array}{l}\text { International Field Experience } \\
\text { (Short Term) }\end{array}$ & $\begin{array}{l}\text { Explore academic content in a purposeful way outside the class room } \\
\text { through short-term field trips and/or field-work (less than } 20 \text { hours) outside } \\
\text { of Canada. }\end{array}$ \\
\hline $\begin{array}{l}\text { International Field Experience } \\
\text { (Long Term) }\end{array}$ & $\begin{array}{l}\text { Intensive and immersive time in the field ( } 21+\text { hours) to study and apply } \\
\text { academic concepts outside of Canada. }\end{array}$ \\
\hline Internship & $\begin{array}{l}\text { Participate in discipline-specific, supervised, full-time work during the study } \\
\text { period ( } 400+\text { hours, paid/unpa id). }\end{array}$ \\
\hline Lab & $\begin{array}{l}\text { Observe, test and apply course concepts in a controlled setting specialized } \\
\text { for small group leaming (typically affiliated with specific technology and/or } \\
\text { facilities). }\end{array}$ \\
\hline Practicum & Supervised, practice based experience in employment related field of study. \\
\hline
\end{tabular}




\begin{tabular}{|l|l|}
\hline Professional Practicum & $\begin{array}{l}\text { Supervised, practice-based experience required for professional licensing or } \\
\text { certification. }\end{array}$ \\
\hline Project Activities & $\begin{array}{l}\text { Develop and complete a project as an independent study working } \\
\text { individually or in small groups with a faculty member(s). }\end{array}$ \\
\hline Simulations \& Experimentation & $\begin{array}{l}\text { Engage with academic content through content-specific activities such as } \\
\text { simulations, demonstrations, archival or design work, role play and/or case } \\
\text { studies. }\end{array}$ \\
\hline Service-Learning & $\begin{array}{l}\text { Address a community need (on campus or beyond) in a reciprocal } \\
\text { partnership through the integration of course content, academic theory and } \\
\text { assessed critical reflection to produce meaningful outcomes in personal, } \\
\text { academic and civic learning. }\end{array}$ \\
\hline
\end{tabular}

Additional opportunities to gain meaningful experience as part of broader academic programs or co-curricular opportunities are also part of the Brock experience and outlined below:

\begin{tabular}{|l|l|}
\hline Co-Curricular/Additional Opportunities \\
\hline $\begin{array}{l}\text { Campus Wide Co-Curriculum } \\
\text { (CWC) }\end{array}$ & $\begin{array}{l}\text { Develop, enhance, and/or improve your understanding and skills from ten } \\
\text { themed domains within the CWC designed to help navigate the many } \\
\text { opportunities to engage in activities outside the classroom both on or off } \\
\text { campus. (i.e. volunteering, university governance, peer tutoring, learning } \\
\text { skills workshops, career development sessions, athletics, etc.) }\end{array}$ \\
\hline Entrepreneurship \& Innovation & $\begin{array}{l}\text { Cultivate, organize and/or manage a bus iness, social enterprise or creative } \\
\text { idea from development through implementation. }\end{array}$ \\
\hline Student Lead Initiatives & $\begin{array}{l}\text { Participate in a club, conference, or competition. (i.e. Business Students' } \\
\text { Association, Model UN, etc.) }\end{array}$ \\
\hline $\begin{array}{l}\text { Publication or Conference } \\
\text { Presentation }\end{array}$ & $\begin{array}{l}\text { Present and/or publish an original work or contribute to a publication in an } \\
\text { editorial, original author or co-author capacity including open access } \\
\text { publishing and the Brock digital repository. }\end{array}$ \\
\hline Study Abroad or Exchange & $\begin{array}{l}\text { Study internationally for one term, academic credit, and/or additional } \\
\text { degree. }\end{array}$ \\
\hline $\begin{array}{l}\text { Teaching and/or Research } \\
\text { Assistantship }\end{array}$ & $\begin{array}{l}\text { Gain experience with teaching and classroom facilitation as part of a } \\
\text { graduate or undergraduate programs. }\end{array}$ \\
\hline VITAE (Graduate Students Only) & $\begin{array}{l}\text { Design, build and participate in essential professional skills training sessions } \\
\text { and programs that assist you in developing, translating and expressing your } \\
\text { experiences, academic and professional skills. }\end{array}$ \\
\hline
\end{tabular}

We would like to acknowledge the University of Victoria for their consultations, as well as the faculty, staff and students who took time to engage in the comversation that has shape our definitions for the future development of experiential education at Brock.

Final version established November 22, 2016. Brock University. 


\section{Appendix B}

\section{Common Language for Experiential Education}

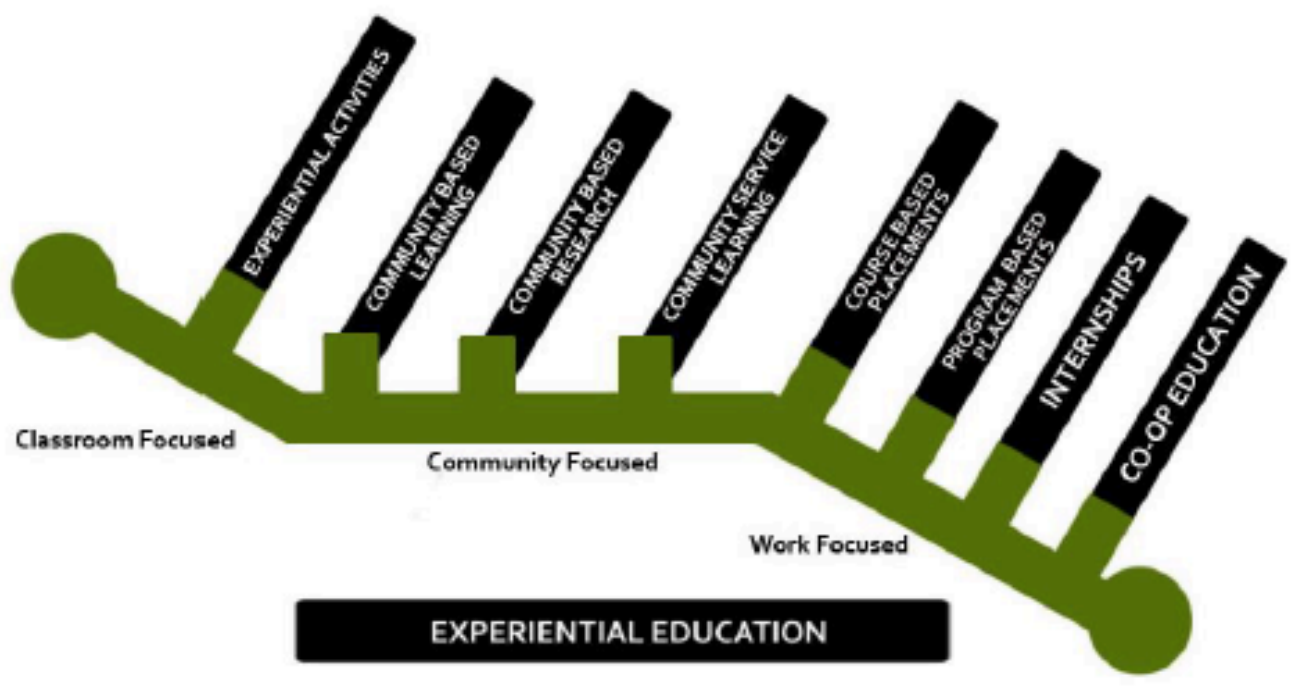

Definition of Experiential Education (EE)

"EE is an approach to learning that bridges theory and practice by providing students with concrete applied practical experiences and then helping them to reflect on their experiences using the theoretical knowledge they have learned (York's White Paper Companion, 2010:38)."

\section{Definition of Structured Reflection}

Structured reflection is any planned activity or exercise that requires students to refer back and critically examine the concrete experience in light of existing theory and/or what is being covered in the course. For example, following a concrete experience, students may have to: explain why certain events occurred, or justify the necessity of certain procedures, or consider the experience from multiple perspectives or challenge their assumptions or beliefs. The specific reflective learning exercise will depend upon the intended learning outcome(s) for the students.

Note: It is important that steps are taken to ensure that degree programs incorporate EE across a range of courses at different levels. Early experiences in developing reflective thinking and collaborative learning through classroom-focused activities serve as building blocks for community and work-focused opportunities later in the student's degree program, preparing students to experience deeper learning and adapt to workplace teams. All EE activities should be fully integrated into the course with explicit links to student learning outcomes (and course assessment strategies).

\section{EE STRATEGIES}

1. Classroom-focused

2. Community-focused

3. Work-focused (work-integrated learning) 
1. CLASSROOM-FOCUSED EE: Students are exposed to concrete learning activities in the classroom (physical or virtual, e.g., online) that require them to reflect on what they have experienced in relation to concepts/theories being covered in the course. All classroom focused EE strategies contribute to addressing student learning outcomes.

1. a) Experiential Activities: This experiential education strategy allows students to apply theory and course content to concrete experiences that encourage reflection and conceptualization. These experiences not only encourage active learning but also include structured reflection, encouraging the student to refer back to the experience in an effort to make sense of it by considering relevant course material. These concrete experiences could take place within the classroom or outside the classroom through observation, reflection and practical applications. They are combined with purposeful reflective learning exercises such that the experience is considered in relation to the concepts/theories addressed in the class.

Wherever they occur, they count as classroom-focused EE because they prioritize student learning outcomes over reciprocal impact within community.

Key features:

How do students engage in EE? Within the classroom through the use of guest speakers. rehearsals and performances, role playing. visual media, case studies, simulations, workshops and laboratory courses, course-based research or outside of the classroom through interviews with professionals in a particular field, participation in community events, observations of lived experiences that correlate with topics under study, and visits/field trips to sites that are of particular relevance to certain disciplines.

To what extent are community partners engaged/involved? As guest speakers/participants, transferring knowledge and/or subject matter expertise within the classroom or as bystanders being observed within the community.

Is priority given to student learning outcomes or community partner needs? Student learning outcomes for the course are the priority with this type of EE.

How long and how frequently do these experiences occur? Experiential Activities take place throughout the length of the course. Experiential activities make up a significant portion of the course.

How are students remunerated? Students receive academic credit for Experiential Activities. Experiential Activities are unpaid.

2. COMMUNITY-FOCUSED EE: Students have the opportunity to connect course material with experiences that occur through interactions with community partners that can take place in the classroom or in the community. These connections tend to occur in groups/teams focused on a specific project. Reflection remains a key element, which requires students to link the concrete experience with the students' understanding of theory. All community-focused EE strategies contribute to addressing both student-learning outcomes and identified community needs. "Community partners" can refer to small-scale local entities from the public or private sector to large-scale local, national, trans-national, entities such as corporations, government and nongovernmental organizations. Categories of community focused EE include the following.

2. a) Community Based Learning (CBL) is a form of experiential education that is interactive with the community but takes place within the classroom. Community partners are invited into the classroom to present pre-defined problems, questions or issues to be explored and analyzed. 
Students are exposed to scenarios, situations, problems and issues described by the community partners, to which students apply their developing knowledge and reflect on how the actual experience informs their learning. The CBL project benefits both student learning and the community partner.

\section{Key features:}

How do students engage in EE? Students are exposed to scenarios, situations, problems and issues presented by community partners within the classroom, to which they apply their developing knowledge.

To what extent are community partners engaged/involved? The experience requires consultation between the Course Director and the community partner and clarification of expectations in terms of what students can deliver. Community partners may participate in the assessment of the students' work if it involves, for example, reports or presentations.

Is priority given to student learning outcomes or community partner needs? A CBL project is created/structured so that it benefits both student learning and the community partner.

How long and how frequently do these experiences occur? CBL projects can vary in length, from a project that takes place over a few weeks to a project that spans the duration of the course. During CBL students have the ability to work remotely from the organization.

How are students remunerated? Students receive academic credit for Community Based Leaming. Community Based Learning activities are unpaid.

2. b) Community Based Research (CBR) Students are given the opportunity to work on a research project that is part of a course and has been co-created and developed through the collaboration between a community partner and a researcher (e.g., course director). Not only must the CBR activity satisfy the student learning outcomes of the course but it must also satisfy the needs of the community partner. It is: practically relevant to the community: collaborative and action oriented ${ }^{1}$. The CBR project may take the form of an applied independent research study or thesis.

CBR activities are normally completed within the duration of a full-year 6.0 credit course (i.e., 24 weeks), though in some cases these activities are completed in a 3.0 credit course. Community partners often participate in the assessment of the students' work and benefit from this work which may take the form of project reports, presentations, or recommendations.

Key features:

How do students engage in EE? Students may engage by working on a research project developed through the collaboration of a community partner and a researcher.

To what extent are community partners engaged/involved? The experience normally requires a formal agreement between the researcher and the community partner outlining items such as: research ethics, how data will be shared, stored, etc.

Is priority given to student learning outcomes or community partner needs? A research project is created/structured so that it benefits both student leaming and the partner organization.

\footnotetext{
${ }^{1}$ As indicated by the Center for Community based research (http://www.communitybasedresearch.ca)
} 
How long and how frequently do these experiences occur? CBR can vary in length, from a research project that takes place over a few weeks to a research project that spans the duration of the course.

How are students remunerated? Students receive academic credit for Community Based Research. These activities are unpaid.

2. c) Community Service Learning (CSL) This is a form of experiential education where "students engage in activities that address community needs together with structured opportunities intentionally designed to promote intentional learning goals" (www.nsee.org). CSL takes students into the community as part of the learning experience. The real-life situation provides the concrete experience for students to apply their developing knowledge and skills and to deepen their understanding by reflecting on their learning. CSL is often used as a strategy to address not only course-based material but also to help students develop an awareness of the value of civic engagement.

Note: There are forms of Community Service Learning that are co-curricular in nature. They often include volunteering opportunities for students. In such forms, CSL is not-for-credit. For our purposes, we are addressing only academically embedded CSL.

\section{Key features:}

How do students engage in EE? Students may engage by providing direct service (other than research) to the community or by taking on a project defined by a community organization.

To what extent are community partners engaged/involved? Community partners often participate in the assessment of the students and may benefit from this work which may take the form of service and/or project reports, presentations, or recommendations. The experience may require a formal partnership by way of an affiliation agreement between York University and the partner organization outlining items such as obligations of York University, obligations of the partner organization, insurance considerations and other specifics pertaining to the activity.

Is priority given to student learning outcomes or community partner needs? A service learning project or opportunity is structured so that it benefits both student learning and the partner organization.

How long and how frequently do these experiences occur? CSL can vary in length, from a project that takes place over a few weeks to a project that spans the duration of the course. During CSL students work at the community partner's site and keep regular hours.

How are students remunerated? Students receive academic credit for Community Service Learning. Community Service Learning activities are unpaid.

3. WORK-FOCUSED EE: Students have the opportunity to develop competencies and skills and augment the theories/concepts leamed in their degree programs by getting hands-on work experience within organizational environments. Reflection remains a key element, which requires students to link the concrete experience with the students' understanding of theory. All work focused EE strategies contribute to addressing degree level expectations, in particular, the student's ability to demonstrate autonomy and professional capacity. Categories of work focused $E E$ include the following.

3. a) Course-based Placements (CBP) This is a form of experiential education where students have the opportunity to develop competencies and skills and augment the theories/concepts learned in their course by getting hands-on experience within organizational environments. The 
learning emphasizes career exploration and employability/professional skills development (HECQO, Practical Guide for WIL, 2016). (e.g. Communication, Disaster \& Emergency Management, History. Portuguese, Public Policy \& Administration, Work \& Labour Studies and Urban Studies). Students must complete this placement in order to complete/pass the course. They receive course credit but are not (generally) paid.

\section{Key Features:}

How long do students engage in EE? Students engage in activities where they practice the discipline or course specific competencies and skills in an authentic work context.

To what extent are community partners engaged/involved? The experience requires a shared understanding between the Course Director and the partner organization of expectations and student capabilities; as well such placements require a formal agreement between York University and the placement site to address various issues such as confidentiality, insurance coverage, risk management etc.

Is priority given to student learning outcomes or community partner needs? The experience is structured so that it benefits both student learning and the partner organization.

How long and how frequently do these experiences occur? The placement is usually part-time and requires students to periodically retum to class to share their experiences and make meaning of their time with the community partner. The length of the course-based placement typically last the duration of the course.

How are the students remunerated? Course-based placements are required as part of the course. Students are evaluated (e.g. report, sponsor evaluation, self evaluation, etc.) on their placement performance as part of their final grade in the placement course. Placements are unpaid experiences.

3. b) Program-based Placements (PBP): Students are given the opportunity to develop competencies and skills in organizational work environments that augment the theories/concepts learned in academic program settings. Students apply theories and concepts from their program work in a practice-based work environment and reflect upon their actions. Students engage in activities where they practice the discipline or program specific competencies; they receive program credit for doing so but (generally) are not paid. Program-based placements are also known as fieldwork, field placements or practica (e.g. Education, Nursing. Social Economy or Social Work).

\section{Key features:}

How do students engage in EE? Students engage in work activities where they practice the discipline or program specific competencies and skills in an authentic work context.

To what extent are community partners engaged/involved? The experience requires a shared understanding between the academic program and the community partner/placement site of expectations and student capabilities; as well, such placements require a formal agreement between York University and the placement site to address various issues such as confidentiality, insurance coverage, risk management etc.

Is priority given to student learning outcomes or community partner needs? Work is structured so that it benefits both student learning and the partner organization.

How long and how frequently do these experiences occur? The program-based placement experience may be full-time or part-time and requires that students periodically return to class to 
share their experiences and make meaning of their time "in the field". The length of program-based placements can vary depending on the degree requirements for the practicum.

How are students remunerated? Degree-based placements are required as part of the degree program. Students are evaluated (e.g. report, sponsor evaluation, self-evaluation, etc.) on their program-based placement performance as part of their final grade in the program-based placement. Program-based placements are typically unpaid work experiences.

3. c) Internships provide students with the opportunity to augment the theories/concepts learned throughout their degree and develop competencies and skills through hands-on work experience related to their field of study. Internships are paid, full-time, supervised work experiences in which learning is assessed via the student reflecting on their internship experience in the workplace and writing a work term report ${ }^{2}$, which is then reviewed and graded by the faculty supervisor. Internships are generally associated with academic programs that include a practice, service or professionally oriented applications. Unlike co-op students participating in internships students do not alternate work experiences with academic terms.

\section{Key features:}

How do students engage in EE? Students engage in work activities where they practice the discipline or course specific competencies and skills in an authentic work context.

To what extent are community partners engaged/involved? The work experience requires some form of learning agreement that is shared by the employer, the faculty supervisor and the student. The student's work progress is monitored by York University and work performance is supervised and evaluated by the partner organization.

Is priority given to student learning outcomes or community partner needs? Supervised work is structured so that it benefits both student leaming and the partner organization.

How long and how frequently do these experiences occur? Internship work terms typically take place after a student's third year of study for $4,8,12$ or 16 months of consecutive work. Students must return to class for their final year of study.

How are students remunerated? Internships are (generally): zero-credit, optional, one-time work assignments. Students receive a transcript notation - typically a faculty supervisor assigns a pass/fail. Internships are paid work experiences.

3. d) Co-operative Education Programs: Co-op programs provide students with the opportunity to integrate their classroom leaming with hands-on work experience related to their field of study in which they alternate periods of paid, full-time, supervised work experiences with their academic terms. According to Cooperative Education and Work Integrated Learning Canada (CEWIL: http://www.cewilcanada.ca/coop-defined.html) a co-op program is one which alternates periods of academic study with periods of work experience in accordance with the following criteria:

- Each work term is developed in partnership with the employer and approved by the cooperative education program as a suitable learning environment;

- The student is engaged in productive work for which the student receives remuneration;

- The co-op curriculum supports student learning goals, personal evaluation and reflection;

- The student's performance in the workplace is supervised and evaluated by the student's employer;

${ }^{2}$ Best practices dictate that critical reflection about the concrete activity informs the report. 
- The student's progress during their work term is monitored by the co-operative education program;

- Both work and academic terms are full-time and follow a formalized sequence. The total amount of co-op work experience is normally at least $30 \%$ of the time spent in academic study. For programs of two years or less the total amount may be a minimum of $25 \%$. A work term is defined as a minimum of 12 weeks and/or 420 hours full-time paid experience;

- Co-op Programs begin and end on an academic term;

- The student completing multiple work terms is normally exposed to the work environment during more than one season of the year.

Co-operative education programs can be either for-credit or zero-credit endeavours, and are generally noted on the transcript and degree. Co-operative student positions are most often 4 to 8 months in duration, with a commitment of 12-16 months in total over the course of the degree. Given the alternating nature of work and study terms, co-operative education programs tend, in most cases, to necessitate alignment with a trimester system.

\section{Key features:}

How do students engage in EE? Students engage in work activities where they practice the discipline or course specific competencies and skills in an authentic work context.

To what extent are community partners engaged/involved? The work experience requires some form of learning agreement that is shared by the partner organization, the faculty supervisor and the student. The student's work progress is monitored by York University and work performance is supervised and evaluated by the partner organization.

Is priority given to student learning outcomes or community partner needs? Supervised work is structured so that it benefits both student leaming and the partner organization.

How long and how frequently do these experiences occur? Co-op work terms typically take place after a student's second year of study for 4-8 months of consecutive work with a commitment of $12-16$ months in total over the course of the degree (or $30 \%$ of time spent in academic study). Students alternate periods of academic study with periods of work experience.

How are students remunerated? Co-operative education programs can be either for-credit or zerocredit endeavours, and are generally noted on the transcript and degree. Co-ops are typically paid work experiences. 